\title{
ESTRATEGIAS DE INTERNACIONALIZACIÓN DE LA EDUCACIÓN SUPERIOR CHILENA PARA EL DESARROLLO DE UNA COOPERACIÓN POSITIVA
}

\author{
INTERNATIONALIZATION STRATEGIES OF CHILEAN HIGHER \\ EDUCATION FOR THE DEVELOPMENT OF A POSITIVE COOPERATION
}

Freddy Antonio Álvarez Fuenzalida*

\section{Resumen}

Este artículo presenta las principales estrategias que utilizan los actores del nivel de educación superior chilena, para fomentar su internacionalización a nivel de pregrado y desarrollar una cooperación positiva. Para esto, se llevó a cabo un análisis de las propuestas y lógicas de cooperación internacional que manifiestan algunos organismos, tanto a nivel internacional como nacional, además de instituciones de educación superior (IES) con el fin de entender ¿cómo logran desarrollar la cooperación por medio de la internacionalización? y ¿cuáles son las principales estrategias que se utilizan en el sistema de educación superior chileno para fomentar su internacionalización y el desarrollo de una cooperación positiva? Para poder contestar estas preguntas se realizó un análisis de documentos de la Organización para la Cooperación y el Desarrollo Económicos (OCDE), el Ministerio de Educación de Chile (MINEDUC) y la Comisión Nacional de Acreditación (CNA). Además, se realizaron entrevistas y cuestionarios con el fin de tener una perspectiva de las partes participantes sobre cómo se realiza la cooperación internacional.

* Profesor de Estado, Traductor e Intérprete Inglés-Español Mención, Magíster en Estudios Internacionales, Magíster en Inclusión e Interculturalidad Educativa (c). Universidad de Santiago de Chile, USACH. email: freddy.alvarez@usach.cl, ORCID https://orcid. org/0000-0003-0914-4556. 
De acuerdo con lo investigado, se puede concluir que las principales estrategias que se utilizan en el sistema de educación superior chileno son, por una parte, las publicaciones a nivel internacional, con el propósito de fortalecer las relaciones científicas internacionales y la divulgación de conocimiento, y por otra parte, la formación docente en el extranjero con el propósito de fortalecer la movilidad académica.

\title{
Palabras clave:
}

Educación superior, movilidad estudiantil, cooperación internacional, cooperación universitaria, relaciones internacionales, diplomacia.

\begin{abstract}
This article shows the main strategies used by Chilean Higher Education stakeholders to support their internationalization, at the undergraduate level, for the development of a positive cooperation. For this, an analysis was carried out on the approaches and the logics of international cooperation that some organisms, both at the international and national level cooperation, have expressed. Besides, some higher education institutions (IES in Spanish) were included, to understand how these institutions, manage to develop cooperation through internationalization, and what are the main strategies used in the Chilean higher education system to promote its internationalization and the development of positive cooperation? In order to answer this question, a document analysis of the Organization for Economic Co-operation and Development (OECD), the Chilean Ministry of Education (MINEDUC) and the National Accreditation Commission (CNA) was carried out. In addition, an interview and a questionnaire were conducted to obtain the participating parties' perspective on how international cooperation is carried out.

According to the obtained information, we can conclude the main strategies used by the Chilean Higher Education to support its internationalization for the development of a positive cooperation are international publications with the purpose of strengthening international scientific relations and knowledge dissemination, and teacher training abroad with the purpose of strengthening academic mobility.
\end{abstract}




\section{Keywords:}

Higher education, student mobility, university cooperation, international cooperation, international relations, diplomacy.

\section{Introducción}

Los estados se han encargado de incluir a la educación superior en los tratados bilaterales que han desarrollado con sus pares en las regiones del globo, ofreciéndola como un servicio de exportación en diversas modalidades (Frederick, 2005). Por otra parte, han sido las mismas IES las encargadas de desplegar diversas estrategias para incorporarse al ámbito internacional, lo cual se ha desarrollado de manera directa, por medio de redes internacionales de cooperación (Siufi, 2009). Uno de los aspectos relevantes a considerar, es cómo las IES han potenciado su internacionalización a nivel de pregrado, con el fin de desarrollar una cooperación que muestre los lazos positivos que los Estados han creado, siguiendo la herencia del Proceso de Bolonia, firmado en Italia en el año 1999 y que ha sido replicado en diversas partes del mundo, incluyendo a Latinoamérica, aun cuando, a diferencia de lo que ocurre en Europa, en Latinoamérica existe una falta de espacio común, ya sea político, económico o de conocimiento (Brunner, 2008). Sin embargo, bajo una mirada analítica del enfoque constructivista, desarrollar la cooperación en torno a la internacionalización, ha permitido la construcción de estructuras sociales y de agentes en las relaciones internacionales, en donde dicho enfoque se presenta como un conjunto de ideas y pensamientos en un sistema de normas acordadas socialmente en un lugar determinado (Oregioni y López, 2011; Espinoza y Gónzalez, 2015).

Los estudios internacionales se han encargado de revisar los fenómenos que ocurren tanto a nivel micro como macro, es por eso que, dependiendo de la perspectiva con la que se analice, surgen diversos enfoques y/o teorías de las relaciones internacionales. El objetivo de este artículo es dar a conocer las principales estrategias que utiliza la educación superior chilena, a nivel de pregrado, para fomentar su internacionalización y así desarrollar una cooperación positiva. 
Los pasos que se llevaron a cabo para lograr conocer las principales estrategias fueron; a) Identificar los principales lineamientos estratégicos presentes en algunos instrumentos internacionales de promoción de la cooperación internacional desarrollados por la OCDE; b) Analizar algunos de los principales instrumentos y estrategias de cooperación internacional presentes en el sistema de educación superior chileno, a nivel Ministerial y de la CNA; y c) Identificar las estrategias de cooperación internacional utilizadas, a nivel de pregrado, por una universidad pública laica, una universidad privada laica, una universidad privada católica y un centro de formación técnica.

\section{Formulación}

Durante décadas, muchas naciones en el mundo han estado lidiando entre sí por adquirir mayor predominio, tanto territorial como político y económico. Gran parte de esto se ha realizado por medio de lo que se denomina Hard Power o Poder Duro, el cual fundamentalmente radica en el poder nacional por medio del uso de recursos militares y económicos.

Nicolás Creus (2013) señala que el poder no es un concepto fácil de explicar; sin embargo, ayuda a comprender cómo funcionan las relaciones internacionales, ya que por tradición se asocia directamente a la escuela realista y a los análisis que esta ha llevado a cabo, señalando que la política internacional se entiende como aquella lucha constante por el poder.

Posteriormente, surge el concepto de Soft Power o Poder Blando con Joseph Nye en la década del año 1990, para introducirse al debate académico y político. La aparición de este concepto surge en el período de la caída del Muro de Berlín y los incidentes en Tiananmén de 1989. Posteriormente, en el año 1991 ocurre la caída de la Unión de Repúblicas Socialistas Soviéticas (URSS). Estos hechos y otros de la época llevan a la aparición de nuevos paradigmas. De esta manera, el Poder Blando se introducirá con fuerza en el ambiente académico (Nye, 2004). 
Para Nye (2004) el Poder Blando de un país radica en tres fuentes significativas. La primera hace referencia a que este surge por aspectos culturales; es decir, en lugares que son atractivos para otros. La segunda se concentra en sus valores políticos, o sea, cuando se está a la altura, en términos políticos, de países extranjeros. Dicho de otro modo, según Valdés-Ugalde y Duarte (2013), esto es cuando un país ha incluido políticas relacionadas al bienestar mundial, como por ejemplo, su preocupación por el calentamiento global, los derechos humanos y la estabilidad económica y financiera. La tercera se refiere a la política exterior de un país, la que le otorga legitimidad y autoridad moral.

A su vez, Nye (2004) distingue entre la Alta Cultura y la Cultura Popular. La primera incorpora elementos que se relacionan con la literatura, el arte y la educación, elementos que son atractivos principalmente para las élites; mientras que la segunda se enfoca, de manera más específica, en entretenimientos masivos, en donde las personas emplean su tiempo libre para la diversión.

Es así como la educación superior internacional, según Knight (2015) "en su rol de actor político, se encuentra fuertemente atraída hacia el concepto de Poder Blando" (p.10), entendiendo este como "la capacidad de influir sobre otros y de lograr el interés o los intereses propios nacionales, haciendo uso de la atracción y de la persuasión en vez de la coerción, de la fuerza militar y de las sanciones económicas, comúnmente conocidas como Poder Duro (Knight 2015, p. 10).

Se entiende entonces que el Poder Blando, por medio de los aspectos culturales, se comienza a instalar en los procesos de coordinación internacional entre los Estados y sus gobernantes, lo que conllevaría a fortalecer asociaciones de intercambio cultural por medio de la educación, específicamente, la superior.

Entonces, la internacionalización de la educación superior se establece como uno de los ejes fundamentales que permiten dar una orientación más clara, en cuanto a las políticas institucionales. Además, genera un compromiso por parte de las IES, con los desafíos a los cuales este nivel educacional se ve enfrentado (Beneitone, 2014).

De este modo, la internacionalización, como concepto, se vincula más al desarrollo de procesos complejos que sólo a una interrelación 
entre actores, lo que deja ver un alcance mucho mayor y significativo; es decir, no sólo basta con tener actividades internacionales en los ámbitos de la docencia, la investigación o la extensión, sino más bien con incorporar lo internacional en las acciones que las IES realizan. Siendo así, se establece que es importante llegar a la comunidad universitaria y a la de otro tipo de IES para poder alcanzar el estatus de "internacionalizados" (Beneitone, 2014).

Es por esto que la educación superior, como Poder Blando, hoy incluye programas como el Fulbright, las actividades del British Council, las iniciativas del Servicio de Intercambio Académico Alemán, los proyectos Erasmus Mundus, entre otros; los que además son vistos con prestigio y respeto de larga trayectoria, que la comunidad académica y mundial considera como grandes aportes (Knight, 2015).

Los desafíos de establecer la universalidad e internacionalización de la educación superior han conllevado a que se comience a hablar de la ciudadanía global, la internacionalización integral y de la universidad de clase mundial. Es así como las universidades han incorporado este aspecto, tanto en sus misiones como en sus visiones, con el fin de posicionarse y luchar por el mejor lugar dentro de los rankings internacionales. Algunos de estos rankings son, por ejemplo: el Times Higher Education, en donde se presentan las cien universidades más internacionales del mundo y el ranking U Multirank, en donde se publica la clasificación de la orientación internacional de más de doscientas treinta universidades (De Wit, 2015).

De Wit (2015) señala que ambos rankings toman indicadores cuantitativos, como por ejemplo, la cantidad de estudiantes internacionales, la cantidad de personal internacional y las publicaciones internacionales. Sin embargo, el autor se pregunta si en realidad estos indicadores pueden definir en qué consiste una universidad internacional, haciendo referencia al ensayo elaborado por Jane Knight para The State of Higher Education (2014), donde cuestiona qué es una universidad internacional e indica que existe demasiada confusión sobre lo que en realidad le significa a una universidad volverse internacional. Es así como Knight (2014) y De Wit (2015) reconocen tres generaciones de universidades internacionales: a) Una que se ha 
internacionalizado por medio de convenios internacionales, alumnos, personal internacional y actividades de cooperación. b) Otras con oficinas satélites en forma de sucursales de campus, centros de investigación y oficinas de gestión y proyectos. c) Aquellas que han establecido una modalidad conjunta entre dos o más instituciones asociadas de distintos países. A pesar de esto, también se ha considerado la modalidad de internacionalización en casa, la cual consiste en programas de investigación y enseñanza conjunta, donde estudiantes e investigadores colaboran con sus pares en el extranjero. Este tipo de internacionalización provoca que los estudiantes puedan desarrollar un currículum internacional, con una perspectiva internacional y multicultural, pero sin la necesidad de moverse de su propio país (De Wit, 2015).

Según lo establecido previamente, se puede señalar que las IES chilenas se han encargado de desarrollar diversas estrategias que permitan la internacionalización de la educación superior nacional, lo que ha conllevado a que estas instituciones de educación trabajen fomentando la internacionalización de la casa de estudio y también de sus facultades o departamentos, con el fin de ampliar el desarro1lo académico de los estudiantes. Es así que se contemplan diversas actividades y estrategias, tales como pasantías en el exterior, movilidad de estudiantes, acceso a becas y práctica en el extranjero, que ayudan al proceso y progreso de la internacionalización (Pontificia Universidad Católica de Chile, s.f.), la que se entiende, según Knight, como "el proceso de integración de la dimensión global, intercultural e internacional en el propósito, las funciones o entrega de la educación superior" (Knight 2005).

De acuerdo con los puntos previos, y con un afán de describir y abrir el debate respecto a la internacionalización de la educación superior, impartida no sólo por universidades, sino que también por otro tipo de instituciones, tales como los centros de formación técnica, es que se ha querido realizar este estudio, enfocándose en conocer las estrategias que utilizan las IES para lograr su internacionalización a nivel de pregrado.

Según lo antes señalado, el problema de investigación se enmarca en la siguiente pregunta: ¿Cuáles son las principales estrategias 
que se utilizan en el sistema de educación superior chileno para fomentar su internacionalización para el desarrollo de una cooperación positiva?

Por medio de esta pregunta se pretende conocer las estrategias utilizadas para luego reconocer aquellas que tengan mayor preponderancia en el proceso de internacionalización de las IES chilenas, además de señalar el propósito de estas respecto a una dimensión específica, que afecte en mayor o menor medida a la internacionalización de la educación superior nacional y el rol de esta para generar una cooperación de carácter positivo entre los participantes, transformándose, según las palabras de Jane Knight en "diplomacia del conocimiento", ya que "el conocimiento es la piedra angular del mundo interconectado actual" (Knight, 2015, p. 10), y es este el que tiene la responsabilidad de adoptar un rol proactivo en cuanto a las desigualdades existentes a nivel mundial.

Para responder a esta pregunta, se han establecido las siguientes hipótesis: por una parte, se plantea que la principal estrategia que utiliza el sistema de educación superior chileno como fomento de su internacionalización, para el desarrollo de una cooperación positiva, son las publicaciones a nivel internacional con el propósito de fortalecer las relaciones científicas internacionales y la divulgación de conocimiento.

Por otra parte, se establece que la principal estrategia que utiliza el sistema de educación superior chileno como fomento de su internacionalización, para el desarrollo de una cooperación positiva, es la formación docente en el extranjero, con el propósito de fortalecer la movilidad académica.

Estos puntos se desarrollan por medio de: a) la identificación de los principales lineamientos estratégicos presentes en instrumentos internacionales de promoción de la cooperación internacional, desarrollados por la Organización para la Cooperación y el Desarrollo Económico (OCDE), b) el análisis de instrumentos y estrategias de cooperación internacional presentes en el sistema de educación superior chileno, a nivel ministerial y de la CNA (Comisión Nacional de Acreditación) y c) la identificación de las estrategias de cooperación internacional. 


\section{Cooperación Internacional y Educación Superior}

El siguiente apartado describe cómo se comporta la educación superior, según los intereses nacionales y la manera en que esta ayuda en las relaciones internacionales, que presentan los Estados, desde un punto de vista diplomático en virtud de ser considerada un Poder Blando.

\section{La cooperación}

Para Sennet (2012), la cooperación se entiende como el intercambio en el cual quienes participan reciben beneficios, debido a que existe un apoyo mutuo. Según el autor, se encuentra en la genética de los animales sociales, que necesitan de apoyo cuando no logran realizar algo por sí solos. Además, señala que la cooperación puede ser formal o informal, dependiendo de la situación en la que se establezca. Es así como esta podría tomar ribetes negativos, obteniendo resultados destructivos para terceros que no sean parte del mismo grupo de agentes cooperadores. A su vez generaría diversos grupos de cooperación. Sin embargo, los grupos podrían no pretender el bienestar de algunas sociedades; a lo cual se denominaría Cooperación Destructiva. Dicha situación estaría forjada bajo la premisa de que este tipo de cooperación es un "nosotros contra ustedes", en donde se reúnen agentes con distintos intereses e incluso en conflicto, pero que han logrado prever un punto en común; debilitar al otro, como se observa en el caso de las Guerras Mundiales y otras situaciones de conflicto a nivel internacional. Entonces, para lograr una cooperación efectiva y positiva, los gobiernos deben trabajar en conjunto, configurando políticas nacionales que incorporen un enfoque internacional común (Informe Sobre el Comercio Mundial, 2004).

De lo anterior se puede deducir que los Estados se han unido en diversas ocasiones con el fin de lograr un resultado favorable en común, aun cuando estos se han visto en situaciones beligerantes por espacios territoriales y de soberanía o, sólo por mostrar que son más fuertes que otros en el mapa hegemónico; sin embargo, la educación, específicamente la superior, es un recurso poderoso que 
se puede utilizar para afianzar vínculos entre Estados, logrando una Cooperación Positiva, en desmedro de la antes mencionada Cooperación Destructiva. Dicha Cooperación Positiva permitiría encontrar intereses comunes que no perjudiquen a un tercero, sino más bien, que lo inviten a ser partícipe de los beneficios que se propongan.

\section{Educación y diplomacia: poder blando, hegemonía y soberanía}

Patti MacGill (2014) señala que la diplomacia solía ser la responsabilidad de los jefes de Estado, o de sus representantes; sin embargo, en el último tiempo, este aspecto se ha modificado, ya que ha surgido la diplomacia pública, concepto que abarca a más actores, además de ampliar la gama de actividades que tiene como fin promover las relaciones favorables entre Estados. Para llevar a cabo la diplomacia, algunos países de Europa, como Alemania, Italia y Reino Unido han utilizado la educación con el fin de expandir sus intereses nacionales, debido a que esta juega un rol fundamental en el avance de la influencia nacional.

La educación ha permitido que los Estados generen vínculos de relaciones internacionales, bajo términos pacíficos; por esto, la educación superior se considera Poder Blando, ya que privilegia "la fuerza de las ideas y la cultura" para cerrar vínculos de amistad y la disposición de los demás (McGill, 2014).

Cuando las instituciones llevan a cabo sus propios vínculos, nos muestran que actúan de forma paralela en el ámbito de la cooperación y la competencia, no obstante, las instituciones han debido desarrollar sus propias estrategias de compromiso, tales como ofertas de programa de doble titulación o investigación conjunta (McGill, 2014).

Por lo tanto, si se firman acuerdos de cooperación académica, todos sus elementos, ya sean contextuales o formales, son elementos de un acuerdo internacional, pero si las IES los realizan por sí solas no se deben olvidar que se rigen por las leyes nacionales y las costumbres locales y, que al momento de operar por su propia cuenta están procediendo más allá de la soberanía, lo que no les quita su rol de representantes nacionales. Entonces, al igual que en cualquier negociación diplomática, las IES deben desarrollar protocolos 
que abarquen y reconozcan todos los detalles, promesas, compromisos, resoluciones en caso de tensiones y expectativas fundamentales para las partes componentes (McGill, 2014).

La internacionalización de la educación superior se presenta como una inversión de capital humano y no como un simple fin. Katsarova (2015) argumenta que esta es una vía que asegura adecuados beneficios mientras se contribuya a las necesidades de la sociedad, considerando que son cada vez más los jóvenes que desean obtener un título. El 60\% de jóvenes, que pertenecen a países de la OCDE, espera entrar a la educación superior, por lo que se estima que su demanda a nivel mundial se encuentra en aumento, desde los 97 millones de estudiantes en el año 2000 a más de 262 millones para el año 2025 (Aebischer, 2015).

Brunner (2016) señala que Chile, después de Brasil, fue el país latinoamericano que más crecimiento tuvo en su matrícula entre los años 2000 y 2014. Los instrumentos relacionados a la educación superior en Chile, tales como, la gratuidad y las políticas y prácticas de muchas instituciones de educación superior han sido diseñadas para estudiantes de clase media, con dedicación completa y régimen diurno, en programas presenciales de pregrado en la Región Metropolitana; sin embargo, dicho perfil será cada vez menos representativo para el año 2030, por lo que los sistemas institucionales, el apoyo financiero y los aparatos regulatorios deberán adaptarse a la nueva realidad que se aproxima (Bernasconi, 2017).

\section{Operacionalización de la variable}

Para Méndez (1998) la operacionalización de una variable hace referencia a desglosar la variable por medio de un proceso de deducción lógica en indicadores. Dichos indicadores hacen referencia a situaciones de carácter específico de la variable. Los indicadores se pueden medir por medio de índices o pueden ser investigados por ítems o preguntas, que forman parte de los instrumentos que se diseñan para obtener la información requerida (Méndez, 1988, p. 79). 


\section{Cuadro operacional: descripción}

A continuación, se presenta la Tabla 1: Operacionalización de la variable "Internacionalización de la educación superior", la cual fue desglosada en dimensiones y posteriormente en indicadores, que sirvieron para poder elaborar un cuestionario con escala Likert, que se utilizó para llevar a cabo la recolección de datos.

De la variable se han obtenido cuatro dimensiones, y a su vez, desde las dimensiones se ha extraído un total de trece indicadores que sirvieron para obtener información referente a la estrategia de internacionalización que más están utilizando las instituciones nacionales de educación superior, consideradas para este estudio.

Tabla 1. Operacionalización de la variable

\begin{tabular}{|c|c|c|c|c|c|c|c|}
\hline Variable & $\begin{array}{l}\text { Definición } \\
\text { operacio- } \\
\text { nal }\end{array}$ & $\begin{array}{l}\text { Dimen- } \\
\text { sión }\end{array}$ & $\begin{array}{l}\text { Indica- } \\
\text { dores }\end{array}$ & $\begin{array}{l}\text { Técnica } \\
\text { de Reco- } \\
\text { lección } \\
\text { de datos }\end{array}$ & Fuente & $\begin{array}{l}\text { Instru- } \\
\text { mentos }\end{array}$ & $\begin{array}{l}\text { Afirma- } \\
\text { ciones o } \\
\text { pre- } \\
\text { guntas } \\
\text { relacio- } \\
\text { nadas }\end{array}$ \\
\hline \multirow{4}{*}{$\begin{array}{l}\text { Interna- } \\
\text { cionaliza- } \\
\text { ción de } \\
\text { la edu- } \\
\text { cación } \\
\text { superior }\end{array}$} & $\begin{array}{l}\text { Se entien- } \\
\text { de por } \\
\text { "dimensión } \\
\text { interna- } \\
\text { cional" } \\
\text { (interna- } \\
\text { cionaliza- } \\
\text { ción de la }\end{array}$ & \multirow{4}{*}{$\begin{array}{l}\text { Movilidad } \\
\text { Acadé- } \\
\text { mica }\end{array}$} & $\begin{array}{l}\text { Participa- } \\
\text { ción en } \\
\text { eventos } \\
\text { acadé- } \\
\text { micos } \\
\text { interna- } \\
\text { cionales. }\end{array}$ & $\begin{array}{l}\text { Obser- } \\
\text { vación } \\
\text { mediante } \\
\text { encuesta. }\end{array}$ & $\begin{array}{l}\text { Expertos } \\
\text { en vin- } \\
\text { culación } \\
\text { interna- } \\
\text { cional. }\end{array}$ & $\begin{array}{l}\text { Cues- } \\
\text { tionario } \\
\text { con } \\
\text { escala } \\
\text { Likert. }\end{array}$ & $1-13-29$ \\
\hline & $\begin{array}{l}\text { educación } \\
\text { superior) } \\
\text { a las redes } \\
\text { que han } \\
\text { surgido }\end{array}$ & & $\begin{array}{l}\text { Formación } \\
\text { docente } \\
\text { en el ex- } \\
\text { tranjero. }\end{array}$ & $\begin{array}{l}\text { Obser- } \\
\text { vación } \\
\text { mediante } \\
\text { encuesta. }\end{array}$ & $\begin{array}{l}\text { Expertos } \\
\text { en vin- } \\
\text { culación } \\
\text { interna- } \\
\text { cional. }\end{array}$ & $\begin{array}{l}\text { Cues- } \\
\text { tionario } \\
\text { con } \\
\text { escala } \\
\text { Likert. }\end{array}$ & 20 \\
\hline & $\begin{array}{l}\text { importante } \\
\text { de acción } \\
\text { que debe } \\
\text { basarse en } \\
\text { la solida- } \\
\text { ridad, e el } \\
\text { compartir }\end{array}$ & & $\begin{array}{l}\text { Prácticas } \\
\text { en el } \\
\text { exterior. }\end{array}$ & $\begin{array}{l}\text { Obser- } \\
\text { vación } \\
\text { mediante } \\
\text { encuesta. }\end{array}$ & $\begin{array}{l}\text { Expertos } \\
\text { en vin- } \\
\text { culación } \\
\text { interna- } \\
\text { cional. }\end{array}$ & $\begin{array}{l}\text { Cues- } \\
\text { tionario } \\
\text { con } \\
\text { escala } \\
\text { Likert. }\end{array}$ & $10-34$ \\
\hline & $\begin{array}{l}\text { y la equi- } \\
\text { dad entre } \\
\text { las partes } \\
\text { participan- } \\
\text { tes. }\end{array}$ & & $\begin{array}{l}\text { Pasantías } \\
\text { en el } \\
\text { exterior. }\end{array}$ & $\begin{array}{l}\text { Obser- } \\
\text { vación } \\
\text { mediante } \\
\text { encuesta. }\end{array}$ & $\begin{array}{l}\text { Expertos } \\
\text { en vin- } \\
\text { culación } \\
\text { interna- } \\
\text { cional. }\end{array}$ & $\begin{array}{l}\text { Cues- } \\
\text { tionario } \\
\text { con } \\
\text { escala } \\
\text { Likert. }\end{array}$ & $31-32$ \\
\hline
\end{tabular}




\begin{tabular}{|c|c|c|c|c|c|c|c|}
\hline \multirow{8}{*}{$\begin{array}{l}\text { Interna- } \\
\text { cionaliza- } \\
\text { ción de } \\
\text { la edu- } \\
\text { cación } \\
\text { superior }\end{array}$} & \multirow{8}{*}{$\begin{array}{l}\text { Esto se } \\
\text { entiende } \\
\text { como el } \\
\text { evitar la } \\
\text { fuga de } \\
\text { cerebros, } \\
\text { ya que, de } \\
\text { no ser así, } \\
\text { se continúa } \\
\text { privando a } \\
\text { los países } \\
\text { en vías de } \\
\text { desarro- } \\
\text { llo y a } \\
\text { aquellos en } \\
\text { transición, } \\
\text { en cuento } \\
\text { a los altos } \\
\text { niveles de } \\
\text { experien- } \\
\text { cia nece- } \\
\text { saria para } \\
\text { acelerar su } \\
\text { progreso } \\
\text { socioeco- } \\
\text { nómico } \\
\text { (UNESCO } \\
\text { 1998). Ésta, } \\
\text { además } \\
\text { tiende a } \\
\text { generar un } \\
\text { aumento } \\
\text { en las } \\
\text { actividades } \\
\text { de apren- } \\
\text { dizaje, más } \\
\text { allá de las } \\
\text { propias } \\
\text { fronteras } \\
\text { y analiza, } \\
\text { a menudo } \\
\text { en relación } \\
\text { con la } \\
\text { movilidad } \\
\text { estudiantil } \\
\text { y a la coo- } \\
\text { peración } \\
\text { académica. } \\
\text { (Katsarova } \\
\text { 2015). }\end{array}$} & $\begin{array}{l}\text { Movilidad } \\
\text { Acadé- } \\
\text { mica }\end{array}$ & $\begin{array}{l}\text { Movilidad } \\
\text { de estu- } \\
\text { diantes } \\
\text { extranje- } \\
\text { ros. }\end{array}$ & $\begin{array}{l}\text { Obser- } \\
\text { vación } \\
\text { mediante } \\
\text { encuesta. }\end{array}$ & $\begin{array}{l}\text { Expertos } \\
\text { en vin- } \\
\text { culación } \\
\text { interna- } \\
\text { cional. } \\
\text { Expertos } \\
\text { en vin- } \\
\text { culación } \\
\text { interna- } \\
\text { cional. }\end{array}$ & $\begin{array}{l}\text { Cues- } \\
\text { tionario } \\
\text { con } \\
\text { escala } \\
\text { Likert. }\end{array}$ & $4-15$ \\
\hline & & \multirow{3}{*}{$\begin{array}{l}\text { Relacio- } \\
\text { nes cien- } \\
\text { tíficas } \\
\text { interna- } \\
\text { cionales } \\
\text { y divulga- } \\
\text { ción del } \\
\text { conoci- } \\
\text { miento }\end{array}$} & $\begin{array}{l}\text { Investi- } \\
\text { gación } \\
\text { conjunta. }\end{array}$ & $\begin{array}{l}\text { Obser- } \\
\text { vación } \\
\text { mediante } \\
\text { encuesta. }\end{array}$ & $\begin{array}{l}\text { Expertos } \\
\text { en vin- } \\
\text { culación } \\
\text { interna- } \\
\text { cional. }\end{array}$ & $\begin{array}{l}\text { Cues- } \\
\text { tionario } \\
\text { con } \\
\text { escala } \\
\text { Likert. }\end{array}$ & $13-33$ \\
\hline & & & $\begin{array}{l}\text { Redes de } \\
\text { investiga- } \\
\text { ción. }\end{array}$ & $\begin{array}{l}\text { Obser- } \\
\text { vación } \\
\text { mediante } \\
\text { encuesta. }\end{array}$ & $\begin{array}{l}\text { Expertos } \\
\text { en vin- } \\
\text { culación } \\
\text { interna- } \\
\text { cional. }\end{array}$ & $\begin{array}{l}\text { Cues- } \\
\text { tionario } \\
\text { con } \\
\text { escala } \\
\text { Likert. }\end{array}$ & $5-26$ \\
\hline & & & $\begin{array}{l}\text { Publica- } \\
\text { ciones } \\
\text { a nivel } \\
\text { interna- } \\
\text { cional. }\end{array}$ & $\begin{array}{l}\text { Obser- } \\
\text { vación } \\
\text { mediante } \\
\text { encuesta. }\end{array}$ & $\begin{array}{l}\text { Expertos } \\
\text { en vin- } \\
\text { culación } \\
\text { interna- } \\
\text { cional. }\end{array}$ & $\begin{array}{l}\text { Cues- } \\
\text { tionario } \\
\text { con } \\
\text { escala } \\
\text { Likert. }\end{array}$ & $9-12-17$ \\
\hline & & \multirow{2}{*}{$\begin{array}{l}\text { Promo- } \\
\text { ción de } \\
\text { imagen } \\
\text { interna- } \\
\text { cional }\end{array}$} & $\begin{array}{l}\text { Partici- } \\
\text { pación } \\
\text { en ferias } \\
\text { interna- } \\
\text { cionales. }\end{array}$ & $\begin{array}{l}\text { Obser- } \\
\text { vación } \\
\text { mediante } \\
\text { encuesta. }\end{array}$ & $\begin{array}{l}\text { Expertos } \\
\text { en vin- } \\
\text { culación } \\
\text { interna- } \\
\text { cional. }\end{array}$ & $\begin{array}{l}\text { Cues- } \\
\text { tionario } \\
\text { con } \\
\text { escala } \\
\text { Likert. }\end{array}$ & $\begin{array}{c}3-8-18 \\
-28\end{array}$ \\
\hline & & & $\begin{array}{l}\text { Promo- } \\
\text { ción inter- } \\
\text { nacional } \\
\text { específica. }\end{array}$ & $\begin{array}{l}\text { Obser- } \\
\text { vación } \\
\text { mediante } \\
\text { encuesta. }\end{array}$ & $\begin{array}{l}\text { Expertos } \\
\text { en vin- } \\
\text { culación } \\
\text { interna- } \\
\text { cional. }\end{array}$ & $\begin{array}{l}\text { Cues- } \\
\text { tionario } \\
\text { con } \\
\text { escala } \\
\text { Likert. }\end{array}$ & $23-27$ \\
\hline & & \multirow{2}{*}{$\begin{array}{l}\text { Acceso } \\
\text { a coope- } \\
\text { ración } \\
\text { interna- } \\
\text { cional por } \\
\text { medio de } \\
\text { becas y/o } \\
\text { financia- } \\
\text { miento }\end{array}$} & $\begin{array}{l}\text { Acceso a } \\
\text { becas y/o } \\
\text { convenios } \\
\text { interna- } \\
\text { cionales. }\end{array}$ & $\begin{array}{l}\text { Obser- } \\
\text { vación } \\
\text { mediante } \\
\text { encuesta. }\end{array}$ & $\begin{array}{l}\text { Expertos } \\
\text { en vin- } \\
\text { culación } \\
\text { interna- } \\
\text { cional. }\end{array}$ & $\begin{array}{l}\text { Cues- } \\
\text { tionario } \\
\text { con } \\
\text { escala } \\
\text { Likert. }\end{array}$ & $\begin{array}{c}6-11-19 \\
-21-22- \\
25-30\end{array}$ \\
\hline & & & $\begin{array}{l}\text { Financia- } \\
\text { miento de } \\
\text { proyectos } \\
\text { de investi- } \\
\text { gación y/o } \\
\text { académi- } \\
\text { cos con } \\
\text { recursos } \\
\text { externos. }\end{array}$ & $\begin{array}{l}\text { Obser- } \\
\text { vación } \\
\text { mediante } \\
\text { encuesta. }\end{array}$ & $\begin{array}{l}\text { Expertos } \\
\text { en vin- } \\
\text { culación } \\
\text { interna- } \\
\text { cional. }\end{array}$ & $\begin{array}{l}\text { Cues- } \\
\text { tionario } \\
\text { con } \\
\text { escala } \\
\text { Likert. }\end{array}$ & $2-7-16$ \\
\hline
\end{tabular}

Fuente: Elaboración propia. 


\section{Tipo de estudio}

El presente artículo surge desde una investigación de carácter cuali-cuantitativo, que buscaba una explicación comprensiva, de la realidad del objeto en su ámbito natural, para entender el significado de su comportamiento. La revisión de la información se basó en el lenguaje verbal y escrito, por medio del análisis de la información obtenida (análisis del discurso), tanto de las entrevistas cómo de los documentos recopilados, tales como: memorias, estudios, informes, entre otros.

Además, fue de carácter cuantitativo, debido a que los datos recolectados se analizaron por medio de estadística, con el uso del software SPSS Statistics versión 25, para posicionar en orden de relevancia las estrategias de internacionalización, según las respuestas obtenidas por medio del cuestionario con escala Likert, que presentó una escala de cinco niveles. De este modo se podría determinar cuál era la estrategia mayormente utilizada por las IES (Álvarez, Boussac y Szigethi, 2012).

A su vez, fue de tipo descriptivo-exploratorio: descriptivo, porque tuvo como finalidad definir y clasificar el objeto de estudio, señalando características propias y distintivas. Exploratorio, debido a que el tema a investigar no se ha abordado con amplitud. Esto indica que realizar esta investigación significaría obtener información preliminar, la cual permitirá llevar a cabo futuras investigaciones relacionadas a este ámbito (Hernández, Fernández y Baptista, 2006).

\section{Unidad de análisis}

Para desarrollar este estudio se revisó la dimensión internacional de la educación superior, en donde la unidad de análisis a considerar fueron algunos instrumentos y principales estrategias de internacionalización que emplean instituciones de educación superior chilenas.

Además, se convocó a cuatro informantes clave, uno por cada IES, integrantes activos del departamento de relaciones internacionales de las instituciones de educación superior seleccionadas, todas de la Región Metropolitana de Santiago de Chile. 
Su participación consistió en responder una entrevista de preguntas abiertas semiestructurada, la cual fue de utilidad para obtener información sobre las opiniones de los participantes respecto de los estudios internacionales y de las relaciones internacionales de dichas IES; además, sobre los aspectos de cooperación internacional que estas generan por medio de redes. En cuanto a la modalidad de la entrevista, esta fue grabada en audio y posteriormente transcrita por el responsable de la investigación. La duración de la entrevista oral tomó alrededor de sesenta minutos, y se realizó exclusivamente por el investigador, quien, además, fue el custodio de la información.

Para complementar las entrevistas orales, se aplicó un cuestionario con escala tipo Likert, que buscaba identificar la implementación de estrategias de internacionalización por las instituciones de educación superior. Este cuestionario se diseñó en base a indicadores detectados en instrumentos elaborados por el Ministerio de Educación (MINEDUC). El cuestionario consta de treinta y tres afirmaciones, que se responden bajo una escala de valoración de cinco niveles, que va desde el "totalmente en desacuerdo" hasta el "totalmente de acuerdo".

En cuanto a la modalidad del cuestionario, este fue aplicado de manera presencial por el responsable de la investigación y quien, al igual que con el instrumento previo, fue el custodio de la información. Este instrumento se aplicó en no más de quince minutos.

Por otra parte, se revisaron tres documentos elaborados y utilizados por la OCDE: La OCDE Organización para la Cooperación y el Desarrollo Económicos (s.f.), Tertiary Education for Knowledge Society (2008) y Higher Education in Kazakshtan. Reviews of National Policies for Education (2017).

Para analizar los lineamientos del MINEDUC se revisaron los Decretos Supremos de Asignación Presupuestaria para la internacionalización Universitaria $\mathrm{N}^{\circ} 200, \mathrm{~N}^{\circ} 494$ y N 501 .

Respecto a la Comisión Nacional de Acreditación, (CNA-Chile), se revisaron las Resoluciones Exentas NDJ009-4 y la NDJ006-4. Además, se consideró la Guía para la auto-evaluación institucional 
y resolución de acreditación institucional; todos estos documentos obtenidos desde la página web de la CNA, en donde se establecen parámetros que las instituciones de educación superior deben considerar al momento de llevar a cabo el proceso de internacionalización, si corresponde.

El análisis para la obtención de resultados se llevó a cabo por medio de la metodología de análisis de la información (análisis del discurso), modalidad que busca captar, evaluar, seleccionar y sintetizar los mensajes que se encuentren subyacentes en el contenido, tanto de las entrevistas como de los documentos, a partir del análisis de sus significados, en virtud de un problema.

La información obtenida por el cuestionario con escala tipo Likert se analizó por medio de parámetros cuantitativos, tales como: cantidad de estudiantes de pregrado que han realizado prácticas y pasantías en el extranjero; tiempo en el cual se ha realizado promoción internacional y participación en ferias internacionales; cantidad de becas y/o convenios internacionales, etc., todo lo anterior con el fin de identificar los factores que intervienen, para luego establecer un orden proporcional que permita reconocer y determinar las principales estrategias utilizadas por las cuatro instituciones de educación superior participantes, para el cumplimiento de sus propósitos, en relación con la internacionalización del sistema de educación superior chileno.

\section{Muestra seleccionada}

Los casos que se consideraron como muestra para llevar a cabo esta investigación fueron cuatro instituciones de educación superior chilenas. Dentro de los criterios de selección se consideró que fueran: Una universidad estatal laica; una universidad privada laica; una universidad privada religiosa, y un centro de formación técnica. La razón por la cual se han seleccionado estos casos, es porque se intentó representar la heterogeneidad del tipo de Instituciones de Educación Superior.

Se incluyó una universidad estatal laica, debido a que esta institución representa a aquellas que se encuentran bajo el alero 
y la subvención del gobierno nacional, lo que permite conocer las prioridades que el gobierno establece frente a la educación que se encuentra bajo su resguardo, además, representa a una institución que está fuera de un credo en particular, que asegura la libertad de pensamiento en su visión y misión y, en donde la expansión del conocimiento va más allá de algún vínculo dogmático que pueda existir en algún otro proyecto.

Por otra parte, se decidió incluir a una universidad privada laica, debido a que esta podría contar con más recursos para generar internacionalización, considerando que no tiene subvención por parte del Estado; sin embargo, es una de las instituciones de educación superior más grande a nivel nacional. Al igual que en el caso anterior, esta institución es de carácter laico, encontrándose fuera de un credo en particular, que asegura la libertad de pensamiento en su visión y misión, y en donde la expansión del conocimiento va más allá de algún vínculo dogmático que pueda existir en algún otro proyecto.

El tercer caso toma una universidad privada, pero esta vez religiosa, específicamente perteneciente a la orden Jesuita y que presenta características sociales muy marcadas, las que son parte de sus programas de estudio, los que intentan promover y maximizar la preeminencia confesional y los asuntos valóricos y dogmáticos específicos. Es importante señalar que esta institución se presenta como abierta, diversa, tolerante e inclusiva.

La última institución que se consideró para esta investigación fue un centro de formación técnica privado, debido a que se quiso revisar el actuar de una IES orientada netamente a la formación de técnicos y cuyas carreras presentan una duración máxima de cinco semestres y no pueden impartir ni licenciaturas ni títulos profesionales. Otro punto que se consideró fue que tampoco tienen la facultad de impartir programas de Magíster ni Doctorado, lo que permitió observar cómo se lleva a cabo su proceso de internacionalización sin considerar la oferta de dichos grados académicos. 


\section{Resultados de la investigación}

A continuación, se presentan los resultados de la investigación, los que en parte se obtuvieron desde un análisis documental interno (del discurso), que permite recuperar información supeditada para luego retransmitirla. Dentro de los elementos que se consideraron en este análisis se encuentra la "descripción característica", por medio de palabras clave, estrategia que permite seleccionar expresiones o términos que representen el contenido general de lo que se analiza. El elemento específico fundamental que se consideró para este estudio fue la internacionalización de la educación superior chilena.

La estrategia de análisis que se utilizó fue de inferencia, ya que esta, según Schank y Abelson (1977), se considera como el núcleo de un proceso de comprensión, por lo que establece el eje de la comunicación. Dentro de la estrategia de inferencia se utilizó la técnica de establecimiento de las relaciones semánticas, con el fin de dar una construcción de relaciones temáticas lógicas.

\section{Resultados de la investigación (relaciones internacionales) obtenidos con análisis de documentos (OCDE/ MINEDUC/ CNA)}

A continuación, se presenta la síntesis de la información extraída y analizada desde algunos documentos elaborados por la OCDE, el MINEDUC y la Comisión Nacional de Acreditación Chile (CNA). Acá se recogen los aspectos relacionados a la internacionalización de la educación superior, con el fin de identificar lineamientos y estrategias de cooperación presentes en la educación superior chilena a nivel internacional, ministerial y de la CNA.

\section{Síntesis del resultado según documentos analizados}

Según los resultados arrojados se puede establecer que para la OCDE la internacionalización es considerada como un elemento que ayudaría a incrementar aspectos relacionados con la economía de los países. Para la OCDE, los países deben poner énfasis en aumentar la calidad de la educación. 
Un punto significativo se observa al establecer que uno de los lineamientos señala que la carrera académica debe ir adaptándose a los cambios, ya que a nivel internacional los Estados han sido asesorados para lograr la equidad educativa, lo que permitiría lograr niveles de equidad mayor entre las sociedades. Esto a su vez, permitiría la mejor convivencia estudiantil a nivel global y ayudaría a la no discriminación por parte de estudiantes de países receptores.

Por parte del MINEDUC y de la CNA se pudo observar que ambos fomentan el desarrollo de redes internacionales y de la constitución de alianzas estratégicas. Es importante establecer que, en el caso de la CNA, que tiene la labor de encargarse de la calidad de la educación superior y de las IES que la imparten, se hace presente en la internacionalización por medio de factores que dicen relación con los procesos de elaboración de un marco educativo a nivel regional, fomentando los vínculos con los países vecinos por medio de la educación superior. Otro aspecto muy importante de considerar es aquel que señala y da facultad, a nivel internacional, al CNA de administrar los procesos de acreditación de programas de pregrado impartidos por IES de diversos países de latino américa, específicamente a los miembros y asociados al MERCOSUR.

Por su parte, el MINEDUC fomenta la internacionalización de las universidades que cumplan ciertos requisitos, establecidos por dicho ministerio. Esto muestra que existe desigualdad respecto de las IES que reciben ayuda financiera, por lo que se infiere que aquellas instituciones que no cumplen con los requisitos establecidos a nivel ministerial, para llevar a cabo el proceso de internacionalización, no serán partícipes de los beneficios de asignación presupuestaria que otorga el MINEDUC. Entonces, se observa que ha sido de suma importancia que las IES generen redes no sólo a nivel internacional, sino que también a nivel nacional, para fomentar el desarrollo de las mismas. Otro punto que dice relación con la desigualdad, es que esta no es específica en cuanto al tipo de institución, ya que dicha asignación, en este caso, se otorga a una universidad pública y a una privada religiosa. Esto nos muestra que aquellas IES estatales que no cumplan con los requisitos explícitos señalados en la glosa 16 del Programa 30, Decreto 200, que reglamenta la asignación 
de recursos para la internacionalización de las universidades, no podrán optar a dicha asignación. El MINEDUC otorga este beneficio a estas dos instituciones porque cumplen con los 7 años de acreditación institucional, imparten más de 10 doctorados y más del 75\% de los programas de doctorado se encuentran acreditados a la fecha de la asignación. Es importante señalar que dicha asignación presupuestaria tiene relación a la impartición de Postgrados.

Tabla 2. Elementos relacionados a la internacionalización

\begin{tabular}{lc}
\hline \multicolumn{1}{c}{ Elemento } & Autor(es) \\
\hline $\begin{array}{l}\text { Incremento económico } \\
\text { Calidad de la educación }\end{array}$ \\
Carrera académica \\
Equidad educativa & OCDE \\
Equidad social & \\
Redes internacionales & \\
Alianzas estratégicas & \\
Calidad de la educación & CNA \\
Marco educativo & \\
Proceso de acreditación & \\
Redes internacionales & \\
Alianzas estratégicas & \\
Requisitos establecidos & \\
Beneficios & \\
Tipos de institución & MINEDUC \\
Posgrados & \\
Instituciones prestigiosas extrajeras & \\
Capacitación de estudiantes extranjeros & \\
Acreditación & Participación para asignación \\
Alianzas estratégicas & \\
\hline
\end{tabular}

Fuente: Elaboración propia

Considerando la información antes mencionada, queda de manifiesto que los institutos profesionales y los centros de formación técnica no tienen derecho a participar de dicha asignación, ya que, si bien podrían tener el máximo de acreditación, lo cual en 
algunos casos es factible, no cuentan con programas de doctorado, lo que los deja inmediatamente fuera de la participación de dicha asignación presupuestaria.

Se deja de manifiesto que, dentro de los lineamientos, el MINEDUC apoya la constitución de alianzas estratégicas con instituciones prestigiosas que se encuentren fuera de Chile. Para el MINEDUC también es importante que las IES puedan captar estudiantes extranjeros, ya que esto posibilita desarrollar vínculos que incrementan la movilidad académica.

Si bien se puede observar una cooperación a nivel regional, los organismos antes mencionados fomentan un vínculo con el globo, de lo cual se puede desprender la existencia de asimetría en todas las direcciones, lo que no expresa que exista dependencia, ni que dicha asimetría sea negativa.

Resultados de la investigación (relaciones internacionales) obtenidos con entrevista a informantes claves

El siguiente apartado muestra la síntesis de las respuestas obtenidas durante las entrevistas que se realizaron a informantes claves de las instituciones de educación superior (IES), que fueron consideradas para este estudio. Esta síntesis entrega las diferencias y similitudes con las cuales se presentan las cuatro IES, al momento de enfrentar la internacionalización de la educación superior, específicamente, contextualizando en el ámbito de las relaciones internacionales.

De la información obtenida, con las entrevistas a cuatro expertos en internacionalización y vinculación con el medio de las instituciones incluidas en este estudio, se puede sintetizar lo siguiente:

En aspectos de acreditación, es importante señalar que sólo tres de ellas se encuentran acreditadas. El informante de aquella que no se encuentra acreditada señala que hay instituciones de calidad que no se han querido someter al proceso de acreditación, mientras que dos de las otras tres señalan que para que haya una buena internacionalización debe haber una buena acreditación. El cuarto infórmate indicó que lo principal es tener las carreras acreditadas, ya que eso da mucho más valor que la acreditación de la misma institución. 
En aspectos de convenios internacionales, todos los encuestados señalaron que son fundamentales para poder generar internacionalización, ya que estos permiten desarrollar redes, lo que ayuda a lograrla. Todas las instituciones participantes en este estudio tienen convenios internacionales.

En aspectos de cooperación internacional, todas señalan que principalmente la cooperación se lleva a cabo entre IES y no de manera tan directa entre IES y gobiernos. Por su parte, el informante clave de la IES laica privada, señala que los gobiernos han jugado un rol muy importante y han sido la cara para que hoy las IES nacionales puedan generar redes en el extranjero.

Respecto a la asimetría que se podría generar, tres de los informantes claves señalan que existe asimetría entre las IES con las cuales tienen convenios, o de las que son parte de la red de cooperación internacional; sin embargo, todos indican que dicha asimetría no es ni tiene por qué ser negativa. Sólo el informante clave de la IES pública laica señaló que sus relaciones suelen ser muy simétricas, ya que las IES con las cuales ellos se relacionan cumplen con características muy similares, ya que son todas públicas, o todas comparten áreas similares de preparación.

En cuanto al ámbito geopolítico, tres de los cuatro informantes claves señalan que la internacionalización de la educación superior ayuda mucho a posicionar a Chile en el plano geopolítico, ya que nos permite no sólo dar a conocer el nombre de una IES, sino que además el de nuestro país. Es importante señalar que el informante clave de la institución privada religiosa mencionó a ProChile y su labor de agrupar IES para viajar en conjunto, lo que ha permitido "visibilizarnos de manera distinta", debido a la imagen de las mismas instituciones y de Chile, como un buen representante regional, económicamente estable; imagen que se refleja hacia el exterior. En este mismo ámbito sólo el informante de la IES privada laica mencionó que geopolíticamente estamos mal, ya que la misma geografía se ha encargado de hacernos ver como el "hijo único" y nos ha llevado a pensar que todo se encuentra bien, cuando en realidad no es así.

Respecto a la fuga de cerebros, el informante clave de la IES 
privada laica y el informante clave de la privada religiosa, creen que se produce fuga de cerebros debido a que, por una parte, aquellos profesionales que han ido a vivir una experiencia en el exterior han sido más valorados que en su propio país. Por otra parte, señalan que algunos de los que salen de Chile por estudios, lo hacen para perfeccionarse en áreas que en nuestro país no tienen el desarrollo que se puede observar afuera.

Los informantes de las IES pública laica y del CFT señalan que no creen que la experiencia en el extranjero genere la fuga propiamente tal. Ambos concuerdan, además, que una vez que se ha terminado la pasantía, la práctica o los estudios formales deben volver a su país de origen para dar término a los estudios, o en algunos casos para retribuir, cuando la salida la han hecho con fondos externos.

En cuanto al tipo de impacto que genera la internacionalización, todos los entrevistados concuerdan que es totalmente positivo, ya que ayuda a abrir otras perspectivas y puntos de vista en cuanto a la tolerancia y a la experiencia. Además, señalan que es muy positivo para la sociedad en general.

En relación con la cooperación entre Estados, tres de los informantes señalan que también tiene un aspecto positivo para estos, ya que permite un acercamiento mayor entre los mismos y ayuda a generar estándares a nivel regional y mundial en cuanto a requerimientos de calidad de la educación superior.

Solamente el informante de la IES privada laica, cree que la arrogancia del chileno no ayuda a la cooperación entre los Estados, ya que indica que por naturaleza pretendemos ser los mejores de la zona y solo nos comparamos con las grandes potencias.

Según los procesos de internacionalización, todos señalan que están trabajando en generar mejoras, incluyendo la creación de políticas institucionales de internacionalización. En el caso del CFT, el informante señala que no le interesa tener muchos convenios, sino que han estado trabajando en comenzar con pocos, pero que tengan relevancia para lo que ellos pretenden. En el caso de la IES pública laica, el informante señala que están trabajando en mejorar los convenios y en agregar apéndices para la promoción de la internacionalización, específicamente de postgrado. La IES privada laica 
se está haciendo cargo de llevar a docentes y estudiantes a cursos de capacitación en el extranjero y la IES privada religiosa señala que están reforzando sus redes, lo que por ser de carácter religioso ha sido algo inherente a ella, es decir, la red internacional a la cual pertenece esta institución es una red que se encuentra en todo el mundo, por lo que se le hace más fácil generar los vínculos.

Los cuatro informantes señalan, en cuanto a quienes son los beneficiados con la internacionalización, que es la sociedad en general. El informante del CFT señala que, si bien el Estado se beneficia, para que otros también puedan hacerlo, deben estar bajo el alero estatal, de lo contrario no recibe ningún tipo de beneficio.

En relación con el sello distintivo de las IES, estas señalan lo siguiente: la IES pública laica indica que su sello distintivo es el haber decidido apostar por la región y estar fortaleciendo vínculos con México, Brasil, etc., lo que ha permitido dar mayor paso a la movilidad de estudiantes en la región. El informante de la IES privada laica, cree que aún no existe un sello distintivo de esta institución en cuanto a aspectos de internacionalización. Por su parte, la IES privada religiosa deja de manifiesto que su sello lo genera la gran red internacional de contactos, ya que como se señaló previamente, dicha red ha venido de manera natural y ha sido inherente al crecimiento de esta institución, la cual proporciona un sello valórico y social muy marcado. En el caso del CFT, el informante deja de manifiesto que su sello lo marcan las carreras que imparten, ya que son prácticamente únicas en el país y eso hace que sea atractivo, no sólo para aquellos que están terminando su enseñanza media, sino que también para profesionales ya formados a nivel nacional e internacional.

En cuanto a que la internacionalización de la educación superior ayuda a disminuir las brechas económicas, sociales y culturales, todos los informantes concuerdan en que claramente la internacionalización ayuda a aquello, considerando la modalidad que se pretenda implementar. Por otra parte, señalan que la internacionalización ayuda mucho más en el ámbito social y cultural, ya que permite ver realidades que en el país de origen no se conocen.

Respecto al punto que se refiere a cómo los gobiernos se hacen 
cargo de la internacionalización, sólo tres de los cuatro informantes señalan que estos lo hacen por medio del fomento de redes y del otorgamiento de becas, las que, si bien aún no son suficientes, han estado trabajando en ampliarlas e incorporar nuevas. Aquellas que se nombraron en esta entrevista son: Alianza del Pacífico, Becas Chile, CONICYT, Técnicos para Chile. En cuanto al mismo punto, el informante de la IES privada laica señaló que, si bien existen las Becas Chile y CONICYT, estas son insuficientes y que seguirá siéndolo, porque no hay inversión suficiente ni conciencia por parte de los gobiernos.

Refiriéndose a la internacionalización, desde el punto de vista estratégico, dos de los informantes claves señalan que efectivamente la internacionalización representa un eje estratégico a favor de las relaciones internacionales, el cual, además, se debería utilizar para el fortalecimiento de las competencias de los académicos. El informante de la IES privada laica, señala que la internacionalización se ha utilizado más en otros ámbitos, no así en aspecto de educación, ya que otras áreas como lo son la administración y los negocios generan mayor foco que la propia educación. El informante de la IES pública laica señala que si bien, no es lo más relevante, la educación superior como estrategia para las relaciones internacionales, ha ido creciendo exponencialmente. Aun así, no logra tener la relevancia suficiente, ya que el gobierno está mayormente preocupado de generar buenas prácticas diplomáticas y de buenos flujos migratorios, pero lamentablemente esto no se conecta con lo que se puede hacer en el MINEDUC.

Finalmente, lo que dice relación con si la educación superior generaría dependencia, interdependencia o cooperación, tres de los cuatro entrevistados señalan que se genera cooperación y que esta tiene aspectos muy positivos para los actores que están involucrados. El informante de la IES pública laica señala que el afán de este tipo de instituciones no es un afán de pro-dependencia y que, a lo más, se podría encontrar un atisbo de interdependencia, pero nunca desde un punto de vista negativo. Para el informante de la IES privada laica también es cooperación y lo relaciona con lo ocurrido en Europa, señalando que los países trabajan en conjunto, ponién- 
dose de acuerdo para cooperar unos con otros. El informante de la IES privada religiosa también ve cooperación, sobre todo cuando se trata de hablar de las redes a las cuales esta institución pertenece; red que, además, como se mencionó anteriormente, proporciona un sello distintivo muy solidario. El informante del CFT señala que siempre hay un aporte y que ellos también lo son, por lo cual se genera una cooperación muy significativa, en donde se puede intercambiar desde tecnología hasta el conocimiento de habilidades blandas.

\section{Conclusiones}

Los principales lineamientos estratégicos, propuestos por la OCDE, se relacionan con la unificación de criterios vinculados a las estrategias que se deben utilizar para logar una internacionalización coherente, con lo que el plano mundial presenta y solicita.

Uno de los lineamientos más transversales a nivel internacional es aquel que señala la garantía y aumento en la calidad de la educación. Lineamiento en los que, los Estados, han generado iniciativas conjuntas para lograr la equidad y estandarización positiva respecto a la calidad de la educación superior. Es importante mencionar que el Proceso de Bolonia ha sido de gran estímulo para los países latinoamericanos, que han realizado grandes esfuerzos en la unificación de criterios, en el ámbito educacional. Esto se ve sustentado por la OCDE al momento en que esta organización ha puesto como lineamiento aumentar la importancia de la educación universitaria, incentivando la investigación y la innovación. Por otra parte, se puede señalar que el enfoque constructivista de las relaciones internacionales se ve aplicado en el tipo de cooperación que se genera, ya que la internacionalización de la educación superior ha permitido, al igual que lo hizo Europa en su momento, generar un espacio latinoamericano de educación, en donde el Proceso de Bolonia se ha visto replicado en cierta forma en lo que se conoce como ARCUSUR. Si bien no se ha logrado replicar en su totalidad, es decir, que las IES hagan válidos en un cien por ciento los estudios realizados en otro país del grupo MERCOSUR, esto ha propiciado a 
un avance, que con el tiempo podría volver a modificar la actitud de los Estados participantes. Por otra parte, el enfoque constructivista se ve reflejado en el interés que han mostrado los Estados en modificar sus sistemas de educación superior, para lograr una armonía regional y, por qué no decirlo, a nivel mundial. Esto último ha hecho que las mismas instituciones definan y proyecten en sus visiones el desafío de volverse instituciones de clase mundial, acorde a los requerimientos y las modificaciones que conlleva el mundo de hoy.

Un aspecto importante por reconocer es la capacidad que tienen los Estados de utilizar la educación superior como un elemento común, que ha incorporado desafíos positivos, haciendo olvidar, de este modo, los conflictos bélicos que se presentaron en el pasado, específicamente entre Chile y sus vecinos del cono. Es así como, este enfoque constructivista, ha permitido adaptarse a los cambios; situación que los Estados han tenido que estudiar, analizar y aplicar para el desarrollo de una armonía regional y mundial.

Se puede señalar entonces que el objetivo específico que dice relación con identificar los principales lineamientos estratégicos, presentes en los instrumentos internacionales de promoción de la cooperación internacional desarrollados por la OCDE, se ha cumplido en su totalidad.

Del mismo modo que en el caso anterior, se puede indicar que el segundo objetivo específico también se ha logrado en su totalidad. Dicho objetivo pretendía analizar algunos de los principales instrumentos y estrategias de cooperación internacional presentes en el sistema de educación superior a nivel ministerial MINEDUC y CNA.

Por una parte, se trabajó con los Decretos supremos de asignación presupuestaria para la internacionalización universitaria $\mathrm{N}^{\circ}$ 200, $\mathrm{N}^{\circ} 494$ y N 501 del Ministerio de Educación, de los que se pudo inferir que los principales lineamientos que considera el MINEDUC, están principalmente enfocados en fomentar las alianzas estratégicas entre las IES, ya sean estas nacionales o internacionales. En el ámbito internacional, el MINEDUC señala que se deben llevar a cabo dichos vínculos con instituciones de reconocido prestigio, para la realización y desarrollo de programas y proyectos conjuntos, de lo cual se puede inferir un cierto grado de asimetría respecto 
a las IES que generen dichos vínculos. Es importante señalar que dicha asimetría no tiene que, ni debe ser vista, como una acción negativa, sino que, al contrario, podría observarse de manera positiva respecto a los aspectos de cooperación, en cuanto a la generación de vínculos que puedan desplegar aquellas IES con menor posibilidad en su despegue internacional. Es por esto que, además, el MINEDUC presenta como lineamiento la captación de estudiantes extranjeros en programas de postgrado, específicamente en aquellos de Doctorado, lo que se condice con el siguiente lineamiento que avala la movilidad académica internacional, tanto de entrada como de salida. Esto puede generar un mayor vínculo entre las IES y de manera particular, como se señaló anteriormente, estrechar las relaciones entre aquellas que tienen menos experiencia en la internacionalización, con aquellas que presentan un manejo acabado de dicha acción. Estos aspectos deberían extrapolarse con mayor fuerza a la internacionalización de las IES por medio de la educación de pregrado.

En relación con la desigualdad que se pueda generar, el MINEDUC proporciona becas que permiten a aquellas instituciones con menos experiencia, que puedan ir desarrollando estrategias propias para el fomento de la internacionalización, es decir, las IES van ganando experiencia respecto al tema, para luego aplicar lo aprendido y generar postulaciones, no sólo con el gobierno de Chile, sino que también con otros gobiernos a nivel mundial, tal como lo indicó el informante clave de la IES privada religiosa, quien señaló que al ir ganando experiencia con postulaciones a nivel ministerial, luego lo hicieron con algunos gobiernos de Europa, de manera directa o por medio de las mismas instituciones con las que tienen convenios o son parte de su red religiosa. Esto el MINEDUC lo lleva a cabo por medio del MECESUP, ya que se encuentra vinculado al desarrollo institucional.

Respecto a la Comisión Nacional de Acreditación (CNA), queda de manifiesto que los lineamientos y estrategias de internacionalización no son propuestos por la CNA. Sin embargo, las acciones comienzan a nivel nacional dentro de un afán cooperativo, en donde se entrelazan con los aspectos internacionales de la educación superior. 
Es así como se establece que la internacionalización, de la cual es partícipe la CNA, está más asociada a la internacionalización propia de la Comisión y a su participación en redes internacionales para apoyar la calidad de las instituciones y de sus planes y programas de estudio, que a la internacionalización de las instituciones de educación superior propiamente tal.

La Comisión Nacional de Acreditación y los mismos procesos de acreditación, entienden por internacionalización a la promoción y el intercambio de información y de experiencias entre organismos y entidades de Iberoamérica, por medio de la Red Iberoamericana para el Aseguramiento de la Calidad de la Educación Superior (RIACES).

Pese a ello, es importante señalar que, si bien la CNA fomenta la internacionalización de la educación superior, esta no presenta indicadores que la evalúen, ya que no es parte de sus funciones, a pesar de que la CNA trabaja en conjunto con redes internacionales. Aun así, son las propias IES las que se encargan de llevar a cabo la internacionalización. No obstante, tanto la CNA como las redes internacionales de agencias de acreditación, velan por los aspectos de calidad en los programas de pre y postgrado, respetando las reglas jurídicas de cada país.

Dentro de los objetivos que establece RIACES (2019), como red internacional de la cual la CNA forma parte, es que la internacionalización contribuiría a armonizar de manera progresiva el aseguramiento de la calidad de la educación en la región, además, es una instancia que permite colaborar en el proceso de mejoramiento de la calidad de la educación superior en los países de Iberoamérica, en conjunto con entidades, tanto nacionales, como internacionales de cooperación.

Algo muy importante que se pudo observar y que la CNA, en conjunto con otras comisiones de acreditación de otros países tienen previsto en su plan de acción 2017-2019 por medio de RIACES, es crear el Banco de Pares Externos de Iberoamérica para la acreditación institucional, así como también de programas de estudio.

Otra manera de entender el concepto de internacionalización, tanto para la CNA como para los procesos de acreditación, es que esta se vea como la tendencia internacional para otorgar prioridad 
a los asuntos referentes a la calidad de la educación. De este modo, dichos procesos se deberían considerar, particularmente en la agenda 2030. A su vez, tanto para la CNA de Chile como para las de Iberoamérica, la internacionalización es vista como la movilidad de la comunidad académica y el reconocimiento de títulos para movilidad laboral, además de la facilitación de acceso a la educación superior en los países de las agencias participantes en RIACES.

Un punto por destacar, fundamental para esta investigación, es que la CNA tiene una participación activa en cuanto a su aporte de cooperación para el bloque MERCOSUR, lo que nuevamente conlleva a recordar el Proceso de Bolonia y el legado que este ha dejado para América Latina, a pesar de haber sido generado entre países europeos. También se debe destacar la iniciativa generada por los Ministros de Educación de los países miembros y asociados del MERCOSUR de haber propiciado las instancias de reunión, que han permitido estandarizar y cumplir con los lineamientos que la OCDE establece, específicamente en nuestra región.

En cuanto a las características que debe tener la internacionalización, para la CNA esta debe ser transparente y transversal, sobre todo entre aquellos países que pertenecen al bloque de MERCOSUR. Una característica muy relevante es que la internacionalización no debe ser estática, sino más bien debe ir adaptándose y variando según el contexto global, nacional e institucional en el que se lleva a cabo la educación superior, es por esto que la red de Comisiones Nacionales de Acreditación estableció un nuevo ciclo de evaluación y revisión, tanto de documentos como de los criterios para el proceso de acreditación internacional de aquellas carreras incorporadas.

Dentro de las acciones que se deben tomar a mediano plazo, por parte de la CNA y todas las agencias participantes de RIACES, se encuentra la identificación de los países que carezcan de agencia de evaluación, con el fin de realizar asistencia técnica. Por otra parte, las redes internacionales pretenden contribuir con el desarrollo progresivo de un sistema de acreditación que apoye el reconocimiento de títulos y grados académicos, con el fin de que los estudiantes y/o personal académico y/o profesional puedan ejercer sin problemas en los países que formen parte de las redes internacio- 
nales de acreditación, para lo cual se ha establecido como plan de acción un convenio con la UNESCO - IESALC, que permita fomentar la homologación de títulos en Iberoamérica.

De lo antes señalado, se puede deducir que, si bien el Proceso de Bolonia se ha replicado en los países de América, esto no ha sido en su totalidad, ya que por el momento no existe un sistema consolidado de homologación de títulos, por lo que entonces, el proceso de ejercer en un país distinto al de origen o al de donde se estudió no es fluido, sino más bien, engorroso y burocrático, lo que entorpece y repercute de manera directa en los procesos de migraciones internacionales.

En términos generales, se concluye que a pesar de que la CNA fomenta la internacionalización, no existen indicadores propuestos por esta, que se relacionen a la misma, ya que la evaluación se lleva a cabo sobre la base de los criterios que se han mencionado previamente. A pesar de lo anterior, la acreditación de postgrados cuenta con criterios asociados a la dimensión internacional, específicamente en lo que respecta a vinculación con el medio, en donde se solicita que los programas identifiquen algunos indicadores, que son analizados en el marco de los criterios correspondientes, siendo parte de los antecedentes observados durante el proceso. Dentro de dichos indicadores se pueden considerar la existencia de convenios (internacionales) y el financiamiento de proyectos de investigación y/o académicos con recursos externos.

En cuanto al tercer y último objetivo específico, que consistió en identificar las estrategias de cooperación internacional utilizadas por una universidad pública laica, una universidad privada laica, una universidad privada religiosa y un centro de formación técnica cabe señalar que: tras analizar los resultados de las encuestas efectuadas a informantes claves, a cargo de la internacionalización de las IES antes señaladas, se puede indicar que existen estrategias de cooperación internacional claramente definidas y que marcan una tendencia.

Dentro de las estrategias más relevantes y utilizadas se encuentran, la formación docente en el extranjero y las publicaciones a nivel internacional; mientras que las prácticas en el exterior y el financiamiento de proyectos de investigación y/o académicos con recursos externos, no cuentan con información relevante para 
poder concluir su nivel de importancia en estas instituciones para el propósito definido.

La estrategia menos precisa, de acuerdo con los resultados obtenidos en esta investigación, es la movilidad de estudiantes extranjeros, factor que podría estar directamente relacionado a la insuficiencia de becas y posibilidades de financiamiento, a la participación en eventos académicos internacionales, a la real participación en pasantías en el exterior y a la real definición de este factor entre las distintas IES participantes; indicadores en los cuales las instituciones gubernamentales deben poner énfasis, según los lineamientos declarados por la OCDE, para garantizar y aumentar la calidad y avanzar en la equidad a nivel mundial. Dentro de estos puntos, es importante señalar que los gobiernos fomentan la internacionalización por medio de redes y del otorgamiento de becas, las cuales, si bien aún no son suficientes, han estado trabajando en ampliarlas e incorporar nuevas. Las que surgen dentro del contexto de esta investigación son: la beca Alianza del Pacífico, Becas Chile, CONICYT y Técnicos para Chile.

Se debe considerar que el tipo de institución, la pertenencia de esta a alguna red internacional y/o sus propósitos individuales, inciden directamente en el proceso de internacionalización con cada una de las dimensiones antes analizadas, información con la que se avala el cumplimiento total del tercer objetivo general.

En base a todo lo anterior, se puede concluir que, actualmente, para un grupo de IES, la principal estrategia de internacionalización de su sistema de educación son las publicaciones a nivel internacional. Si se extrapola esta información a otras IES nacionales y se complementa con información recogida a través de otros instrumentos, la estrategia de internacionalización actualmente utilizada va en línea con lo propuesto por organizaciones internacionales encargadas de fomentar el desarrollo de esta temática. Queda demostrado que los primeros pasos para el cumplimiento de este macroobjetivo están siendo cumplidos para que, en el desarrollo de su progresión, los pilares preestablecidos sean la base para el cumplimiento de la internacionalización de las IES nacionales con características de clase mundial. 
De este modo, la hipótesis de trabajo número 1, que señala que la principal estrategia que utiliza el sistema de educación superior chileno como fomento de su internacionalización para el desarrollo de una cooperación positiva son las publicaciones a nivel internacional, con el propósito de fortalecer las relaciones científicas internacionales y la divulgación de conocimiento, se acepta.

Respecto a este asunto, es importante señalar que el Estado se ha hecho cargo de los aspectos de investigación por parte de algunas IES; por lo que surge una nueva problemática que dice relación con la desigualdad que se genera al momento de establecer los fondos para las instituciones, ya que no todas tienen la misma oportunidad, sólo por el hecho de no ser parte del Consejo de Rectores de Chile (CRUCH); es decir, sólo las universidades del CRUCH reciben un subsidio por parte del Estado denominado Aporte Fiscal Directo (AFD), el cual constituye una serie de beneficios que no están sujetos al logro de metas específicas o explícitas. Se establece que el AFD se utiliza en la ayuda de la eficiencia docente, la calidad de los profesores y la actividad de investigación; esto último conllevaría directamente a impulsar las publicaciones a nivel internacional, como se establece en esta investigación, con el propósito de fortalecer las relaciones científicas internacionales y la divulgación de conocimiento; sin embargo, queda de manifiesto que el AFD, al ser exclusivo para las universidades del CRUCH, no daría paso a beneficios investigativos que pudiesen desarrollar institutos profesionales, centros de formación técnica y/o universidades no pertenecientes al Consejo de Rectores. Por lo tanto, aquellas instituciones que no reciben apoyo gubernamental deben generar redes de contacto nacional e internacional, que permitan el desarrollo de investigación individual o conjunta.

Como información adicional, y según los datos otorgados por el programa MECESUP, la distribución del AFD se realiza otorgando el 95\% a las universidades por tradición histórica, no considerando su desempeño y entregándolo a libre disposición; mientras que el $5 \%$ restante se entrega de forma variable, en donde sí se reconoce el desempeño institucional de las instituciones pertenecientes al CRUCH. Dentro de los puntos que considera esta asignación se 
encuentra: el número de académicos con postgrado y la cantidad de proyectos e investigaciones realizadas. A diferencia del Aporte Fiscal Indirecto (AFI), que se otorga para incentivar a las instituciones a que reciban a los estudiantes con los 27500 mejores puntajes de la prueba de selección universitaria (PSU) en matemáticas y lenguaje, que se hayan matriculado en primer año de estudio; aporte que pretende ser eliminado por la inequidad que genera al momento de ser otorgado y que durante el año 2017 ha tenido una regulación transitoria.

Por otra parte, la hipótesis de trabajo número 2, que indica que la principal estrategia que utiliza el sistema de educación superior chileno, como fomento de su internacionalización para el desarrollo de una cooperación positiva, es la formación docente en el extranjero con el propósito de fortalecer la movilidad académica, se acepta.

Según el punto antes mencionado, es importante indicar que las IES, ya sean estas: centros de formación técnica o universidades privadas o públicas, religiosas o no, están haciendo el esfuerzo de destinar recursos propios para fomentar la capacitación de su cuerpo académico, con el principal propósito de tener una repercusión positiva en el proceso de enseñanza-aprendizaje de sus estudiantes. Además, la formación docente en el extranjero ha permitido que las mismas IES se comiencen a mostrar fuera de sus propios límites territoriales, lo que conllevaría a una ventaja positiva en aspectos de cooperación.

Se deja establecida la necesidad de desarrollar esta investigación de manera más profunda, ampliando las muestras a nivel nacional, con el fin de fortalecer las brechas que puedan descubrirse respecto a la internacionalización de las IES nacionales, en donde se podría vincular un estudio que abarque las políticas migratorias relacionadas al ámbito educacional y de formación académica, que ayuden al desarrollo de la inclusión cultural.

Para finalizar, queda planteada la necesidad de profundizar, por medio de estudios futuros, la incidencia de otros factores que pudiesen ser relevantes en el proceso de la internacionalización del sistema de educación superior chileno, para lograr la equidad declarada como lineamiento por la OCDE, con el fin de aumentar las capaci- 
dades económicas y la generación de una mayor cohesión social, lo que permitiría continuar con la cooperación internacional, pero disminuyendo las asimetrías existentes. Todo esto, fundamentando y reforzando la visión de los Estados frente al desarrollo de una cooperación positiva bajo un marco vinculado al proceso de Bolonia replicado en América Latina.

\section{Referencias}

Aebischer, P. (2015). Universities: Increasingly Global Players. En UNESCO Science Report. Towards 2030 (eds). Perspectives on emerging issues (pp.3-5). Paris: UNESCO.

Álvarez, F., Boussac, P., y Szigethi, M. E. (2012). Condiciones de vulnerabilidad de estudiantes de origen mapuche en primera y segunda generación insertos en la educación técnico-profesional de un colegio ubicado en la comuna de Quinta Normal de la Región Metropolitana. Santiago: Universidad de Santiago de Chile.

Beneitone, P. (2014). De la cooperación internacional universitaria a la internacionalización de la educación superior: ¿cambio de paradigma o maquillaje conceptual? En G. Tangelson (ed.), Desde el sur: miradas sobre la internacionalización (p. 29). Buenos Aires: Ediciones de la UNLA-Universidad Nacional de Lanú.

Bernasconi, A. (2017). Desafíos del futuro de la educación superior chilena. Centro de Politicas Públicas UC (96). Recuperado de: https://politicaspublicas.uc.cl/wp-content/uploads/2017/08/Paper-N\%C2\%B0-96-Desaf\%C3\%ADos-del-futuro-de-la-educaci\%C3\%B3n-superior-chilena.pdf

Brunner, J. J. (2008). El proceso de Bolonia en el horizonte latinoamericano: límites $y$ posibilidades. Recuperado de: https://www.flacsoandes.edu.ec/sites/ default/files/agora/files/1264693983.jjbrunner_u_0.pdf

Brunner, J. J. (coord.) (2016) Educación Superior en Ibero América. Informe 2016. Santiago de Chile: CINDA.

Decreto 200 (2017). [Ministerio de Educación de Chile]. Reglamenta la ejecución de la asignación presupuestaria "Internacionalización de Universidades”. 03 de octubre de 2015. MINEDUC Chile. Disponible en: http:// bcn.cl/2oapm 
Decreto 494 (2017). [Ministerio de Educación de Chile]. Extracto de Decreto de Educación $\mathrm{N}^{\circ}$ 494, de 21 de diciembre de 2017. MINEDUC, Subsecretaría de Educación Chile. Disponible en: http://bcn.cl/2oapl

Decreto 501 (2017). [Ministerio de Educación de Chile]. Extracto de Decreto de Educación $\mathrm{N}^{\circ}$ 501, de 21 de diciembre de 2017. MINEDUC, Subsecretaría de Educación Chile. Disponible en: http://bcn.cl/2oapk

Creus, Nicolás. (2013). El concepto de poder en las relaciones internacionales y la necesidad de incorporar nuevos enfoques. Estudios internacionales (Santiago), 45, 63-78.

De Wit, H. (2015). ¿Es la universidad internacional el futuro para la educación superior? International Higher Education: The Boston College Center for International Higher Education, 80, 8-9.

Espinoza, O. y Gónzalez, L. (2015). Impacto del acuerdo de Bolonia en el sistema de educación superior en Chile. En M. d. Pinto de Almeida, A. Fávero, y A. Catani, O espacio europeu de educação superior (EEES) para além da Europa (pp. 109-149). Curitiba: Editora CRV.

Frederick, P. (2005). Educación y comercio en tiempos de globalización. Santiago: LOM.

Hernández, R., Fernández, C., y Baptista, P. (2006). Metodología de la investigación. México: McGraw Hill Interamericana.

Katsarova, I. (2015). Higher education in the UE: Approaches, issues and trends. European Parliamentary Research Service. Recuperado de: https://www. europarl.europa.eu/thinktank/en/document.html? reference=EPRS_ IDA(2015)554169

Knight, J. (2005) An internationalization model: responding to new realities and challenges. En H. De Wit, I. Jaramillo, J. Gacel-Ávila, y J. Knight, Jane (eds.). Higher Education in Latin America. The international dimension (pp. 1-38). Washington, D.C.: The World Bank.

Knight, J. (2014). What is an international university?. En A.Glass (ed.). The state of higher education 2014 (pp. 139-143). Paris, Francia: Organisation for Economic Co-operation and Development.

Knight, J. (2015). Pasar del poder blando a la diplomacia del conocimiento. International Higher Education: The Boston College Center for International Higher Education, 10. Recuperado de: http://ceppe.uc.cl/images/stories/ recursos/ihe/Numeros/80/Higher_80.pdf 
McGill, P. (2014). Diplomacia y educación: un panorama mundial en el constante cambio. Recuperado de: http://ceppe.uc.cl/images/stories/recursos/ ihe/Numeros/75/articulo01.pdf

Méndez, C. (1988). Metodología: Guía para elaborar diseños de investigación en ciencias económicas, contables, administrativas. Santa Fe de Bogotá: McGraw-Hill.

Nye, J. (2004). Soft Power and Higher Education. Cambridge Massachusetts: Harvard University.

Organización para la Cooperación y el Desarrollo Económicos. (2008). Tertiary Education for the Knowledge Society. OCDE. Recuperado de http:// www.oecd.org/education/skills-beyond-school/41266690.pdf

Organización para la Cooperación y el Desarrollo Económicos. (2017). Higher Education in Kazakhstan 2017, Reviews of National Policies for Education. París: OCDE Publishing. Recuperado de: http://dx.doi.org/10.1787/9789264268531-en

Organización para la Cooperación y el Desarrollo Económicos. (s.f.) La OCDE Organización para la Cooperación y el Desarrollo Económicos: ¿Qué es la OCDE? Centro de la OCDE en México para América Latina. Recuperado de: https://www.oecd.org/centrodemexico/46440894.pdf

Organización Mundial de Comercio. (2004). Informe sobre el comercio mundial 2004. Recuperado de: https://www.wto.org/spanish/res_s/booksp_s/ anrep_s/world_trade_report04_s.pdf

Oregioni, M. y López, M. (2011). La gestión de la cooperación internacional en la Universidad argentina. Cuadernos del Cendes, 28, 49-65.

Organización de las Naciones Unidas para la Educación, la Ciencia y la Cultura. (2013). Situación educativa de América Latina y el Caribe: Hacia la educación de calidad para todos al 2015. Santiago: OREALC/UNESCO. Recuperado el septiembre de 2017, de http://www.unesco.org/new/fileadmin/ MULTIMEDIA/FIELD/Santiago/images/SITIED-espanol.pdf

Pontificia Universidad Católica de Chile. (s.f.). Internacionalización. Recuperado el 2017, de Faculta de Historia, Geografía y Ciencia Política: http:// historia.uc.cl/Internacionalizacion/internacionalizacion.html

Pontificia Universidad Católica de Chile. (s.f.). Relacionesinternacionales.uc.cl. Recuperado el 2017, de http://relacionesinternacionales.uc.cl/alumnos-uc/pregrado/doble-grado 
Red Iberoamericana para el Aseguramiento de la Calidad en la Educación Superior (RIACES)(28 y 29 de mayo de 2017). Estatutos. Recuperado de: http://riaces.org/estatuto-riaces/

Resolución Exenta DJ009-4 (2014) Aprueba el reglamento que fija el procedimiento para el desarrollo de los procesos de acreditación institucional. [Comisión Nacional de Acreditación CNA]. 13 de octubre de 2014. Santiago de Chile. Recuperado de: https://www.cnachile.cl/docs/transparencia/009-4.pdf

Resolución Exenta DJ006-4 (2016) Aprueba modificación a los criterios para la acreditación de carreras profesionales, carreras profesionales con licenciatura y programas de licenciatura. [Comisión Nacional de Acreditación CNA]. 24 de mayo de 2016. Santiago de Chile. Recuperado de: https://www.cnachile.cl/docs/transparencia/006-4.pdf

Schank, R. y Abelson, R. (1977). Scripts, Plans, Goals and Understanding: an Inquiry into Human Knowledge Structures. Hillsdale, NJ: Psychology Press. SPSS Statistics (Versión 25). (1968). [Programa estadístico informático]. IBM. Sennet, R. (2012). Juantos: Rituales, placeres y politica de cooperación. Barcelona: Editorial Anagrama S.A.

Siufi, G. (2009). Cooperación internacional e internacionalización de la educación superior. Educación superior y sociedad / Nueva época, 14, 119-145.

UPAO, Universidad Privada Antenor Orrego. (2013). Movilidad académica de alumnos y profesores de la universidad: Normativa. Recuperado de: http:// www.upao.edu.pe/convenios/MOVILIDADACADEMICA.pdf

Valdés-Ugalde, J. y Duarte, F. (2013). Del poder duro al poder inteligente. La nueva estrategia de seguridad de Barack Obama o de la sobrevivencia de la política exterior de Estados Unidos. Norteamérica, 8, 41-69. 